\title{
First report of Cucumber green mottle mosaic virus (CGMMV) symptoms in watermelon used for the discrimination of non-marketable fruits in Israeli commercial fields
}

\author{
V. Reingold ${ }^{1}$, O. Lachman ${ }^{1}$, A. Koren ${ }^{2}$ and A. Dombrovsky ${ }^{1 *}$ \\ ${ }^{1}$ Department of Plant Pathology, ARO Volcani Center, P.O. Box 6, Bet Dagan 50250, Israel; ${ }^{2}$ Hishtil Nurseries, Moshav \\ Nehalim, Israel
}

*E-mail: aviv@agri.gov.il

Received: 17 Apr 2013. Published: 12 Nov 2013. Keywords: Tobamovirus, peduncle

The tobamovirus, Cucumber green mottle mosaic virus (CGMMV) causes severe disease of cucurbits worldwide. The typical symptoms in watermelon (Citrullus lanatus) including leaf mottling and mosaic have been reported in greenhouse-grown plants (Varveri et al., 2002, Shim et al., 2005), but these symptoms are masked in plants growing in open fields. Fruit symptoms revealed only after harvest include exocarp deterioration and rotting or yellowing of the fleshy mesocarp (Fig. 1 A-C), causing severe economic losses to the growers, and potentially ruining their reputation if fruits are marketed.

Interestingly, symptoms of necrotic (brown) spots on the peduncle (Fig. 1 D-F) were found to occur simultaneously with fruit flesh symptoms characteristic of viral disease as described above. To assess the association between these symptoms and CGMMV infection, watermelon fruits with brown spots on their peduncles were collected from plants (cvs. Maxima, Trix313, 6003, Tropi, Malali and Crimson) grown in commercial fields in Israel. Five symptom-bearing fruits were tested and found negative for the presence of fungi, oomycetes and bacteria. Ten symptom-bearing fruits were tested negative for potyviruses and begomoviruses. Then, 37 symptom-bearing fruit samples tested positive in ELISA using CGMMV antibodies (Agdia). In addition, virus particles were purified (Tung \& Knight, 1972) from ten symptomatic fruits (100 g peel per fruit), demonstrating the typical tobamovirus rod-shape morphology using transmission electron microscopy (Fig. 2). The purified virion samples were then used for RNA purification (Rosner et al., 1983), followed by reverse-transcription PCR amplification using CGMMV primers flanking the capsid and movement proteins (position 4989 bp 5'-CATAGATGTCTCTAAGTAAGGTG-3' and position 6258 bp 5'-CCCTCGAAACTAAGCTTTCG-3') (Fig. 3). Three PCR products were cloned and sequenced in both directions then aligned with the GenBank database, showing a high degree of identity (99\%) with CGMMV (GenBank Accession No. DQ767631). The purified viral RNA was subjected to SOLiD next-generation sequence analysisfrom which the complete CGMMV genome sequence was obtained (KF155230).

Furthermore, the symptom-bearing peduncles were used for mechanical inoculation of susceptible watermelon (cv. Malali), cucumber (Cucumis sativus cv. Beit Alpha) and Nicotiana benthamiana plants, using carborundum dust and phosphate buffer $\mathrm{pH}$ 7.0. CGMMV symptoms appeared two weeks after inoculation on all test plants and the infections were confirmed by ELISA. Nine CGMMV-inoculated watermelon cv. Malali plants were grown to fruit-bearing following manual pollination in a greenhouse in one-litre plant pots, conditions far different from those of commercial fields. In this case, fruits on three plants presented the necrotic symptoms on stem and peduncle. It is possible that unknown factors present in the field contribute to the differences in symptom intensity observed in field and greenhouse.

This study reports for the first time that necrotic spots on the peduncle occur simultaneously with CGMMV fruit symptoms in watermelon. The association between these symptoms and CGMMV infection has been observed over the last three years in watermelons grown in distinct geographical areas: the Arava and Jordan valleys and central parts of Israel. Since these symptoms were discovered and validated (current study), Israeli growers have been using them to successfully identify and eliminate symptomatic watermelon fruits in the field before harvest. The early elimination of low-quality fruits prevents purchasers from refusing or returning produce thus reducing unnecessary costs (harvest, packing, delivery etc.) and helping to protect the growers' reputation.

\section{Acknowledgements}

This work was supported by the Chief Scientist, Ministry of Agriculture (Israel), project number 132-1479. Contribution from the Agricultural Research Organization, The Volcani Center, Bet Dagan, Israel, No. $520 / 13$.

\section{References}

Rosner A, Ginzburg I, Bar-Joseph M, 1983. Molecular cloning of complementary DNA sequences of citrus tristeza virus RNA. Journal of General Virology 64, 1757-63.

[http://dx.doi.org/10.1099/0022-1317-64-8-1757]

Shim CK, Han KS, Lee JH, Bae DW, Kim DK, Kim HK, 2005. Isolation and characterization of watermelon isolate of Cucumber green mottle mosaic virus (CGMMV-HY1) from watermelon plants with severe mottle mosaic symptoms. The Plant Pathology Journal 21, 167-71. [http://dx.doi.org/10.5423/PPJ.2005.21.2.167]

Tung JS, Knight CA, 1972. The coat protein subunits of cucumber viruses 3 and 4 and a comparison of methods for determining their weights. Virology 48, 574-81. [http://dx.doi.org/10.1016/0042-6822(72)90068-2] Varveri C, Vassilakos N, Bem F, 2002. Characterization and detection of Cucumber green mottle mosaic virus in Greece. Phytoparasitica 30 , 493-501. [http://dx.doi.org/10.1007/BF02979754]

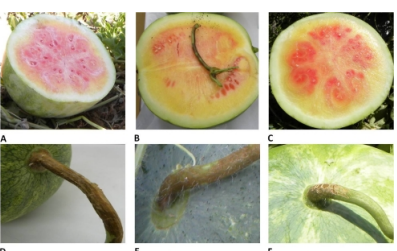

Figure 1

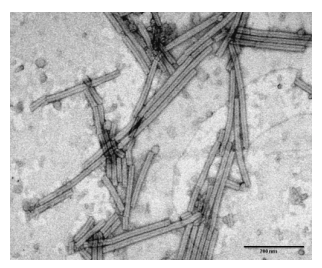

Figure 2

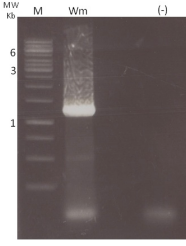

Figure 3

To cite this report: Reingold V, Lachman O, Koren A, Dombrovsky A, 2013. First report of Cucumber green mottle mosaic virus (CGMMV) symptoms in watermelon used for the discrimination of non-marketable fruits in Israeli commercial fields. New Disease Reports $\mathbf{2 8}, 11$. [http://dx.doi.org/10.5197/j.2044-0588.2013.028.011] 